\title{
Como encontrar a história do espetáculo: uma pesquisa em acervos sobre a obra de Carlos Alberto Soffredini
}

How to find the history of a theater-show:

a research made in archives about

Carlos Alberto Soffredini's work

\author{
Maria Emília Tortorella \\ Larissa de Oliveira Neves
}

Maria Emília Tortorella

Doutoranda do Programa de Pós-Graduação

em Artes da Cena da Unicamp.

Larissa de Oliveira Neves

Professora do Departamento de Artes Cênicas da Unicamp e coordenadora do Grupo de Estudos de Dramaturgia Letra e Ato.

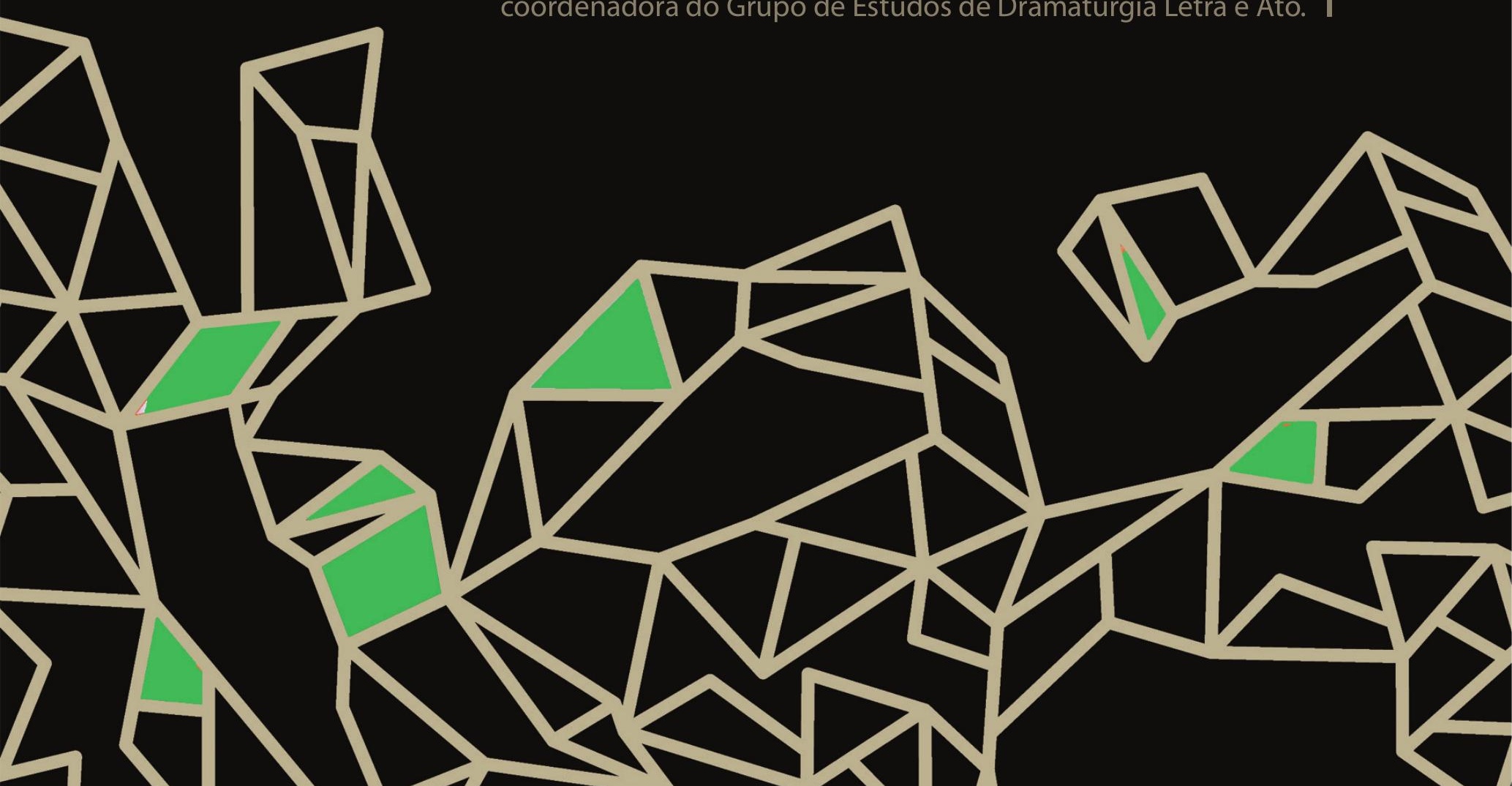




\section{Resumo}

Este artigo apresenta uma proposta metodológica de pesquisa em acervo para análise da dramaturgia e dos espetáculos de Carlos Alberto Soffredini. Após uma apresentação sobre a importância de se buscar fontes de investigação primárias para o (re)conhecimento de diversas etapas do teatro brasileiro, o texto descreve o percurso de levantamento de materiais sobre as peças escritas por Soffredini e sobre sua vida e obra em geral. $\mathrm{O}$ objetivo consiste em retraçar um caminhar de pesquisa, no intuito de fornecer a outros pesquisadores uma proposta de metodologia de busca de fontes em acervos. Esse exemplo visa trazer à luz, por meio deste artigo, um modelo de trabalho que vem sendo realizado por vários integrantes do grupo de pesquisa Letra e Ato, da Unicamp.

Palavras-chave: Metodologia de pesquisa em acervo, Teatro Brasileiro, Carlos Alberto Soffredini.

\section{Abstract}

This study presents an archive research methodological proposal to analyse Carlos Alberto Soffredini's theater and plays. Following a presentation about the importance of seeking primary research sources for the (re)cognition of the different moments of Brazilian theater, this article describes the materials survey on the plays written by Soffredini as well as his life and work in general. The aim consists in explaining the paths of this archive research to provide an methodology example for other possible researchers. This is a line of work that some members of the research group Letra e Ato (Letter and Act) from Unicamp have been following.

Keywords: Archive research methodology, Brazilian theater, Carlos Alberto Soffredini.

\section{Soffredini e a história recente do teatro brasileiro}

A pesquisa em acervo tem se mostrado fundamental para recuperar a história do teatro brasileiro, o que tem sido realizado cada vez com mais constância por pesquisadores acadêmicos. Para análise da cena brasileira do século XIX e da primeira metade do século XX, a busca de informações 
em fontes primárias, como jornais e revistas, torna-se em muitos casos a única opção. Somente no garimpar de acervos de bibliotecas e arquivos, por notícias, anúncios, programas, cartas e, eventualmente, por uma ou outra fotografia, viabiliza-se a produção de conhecimento. Os documentos trazem dados sobre encenações, recepção de crítica e de público, trajetória de artistas. Esse tipo de trabalho garimpeiro tem sido a base para as pesquisas sobre teatro brasileiro desenvolvidas em uma ramificação do grupo de pesquisa Letra e Ato ${ }^{1}$, da Universidade Estadual de Campinas (Unicamp), do qual fazem parte as autoras deste texto, Maria Emília Tortorella e Larissa de Oliveira Neves.

Neves se deparou com a necessidade vital de ocupar-se com o material jornalístico desde o começo de suas pesquisas sobre o teatro brasileiro do século XIX. Já havia desbravadores nesse sentido, professores cujos trabaIhos serviram e servem de modelo metodológico, mas o período investigado então (a virada do século XIX para o XX) contava com pouquíssimas obras de referência ${ }^{2}$. Não fossem os materiais esquecidos nos acervos de bibliotecas e museus, ou o minucioso trabalho de localizar documentos, pouco seria possível analisar. Havia estudos de fôlego - baseados em pesquisa em acervos documentais - sobre períodos anteriores, efetuados por professores como Décio de Almeida Prado $(1972,1996)$ e João Roberto Faria $(1987,1993)$. Tais nomes abriram caminho para diversos outros estudiosos que se seguiram.

O trabalho deu origem à dissertação de mestrado (NEVES, 2002) e à tese de doutorado (Id., 2006) sobre Artur Azevedo, ambas calcadas nas fontes primárias levantadas - em especial crônicas jornalísticas, mas também anúncios, cartas, charges e fotografias. As duas pesquisas deram origem ao livro publicado em 2009, no qual se disponibilizou, em CD acoplado, toda a coleção de crônicas de Artur Azevedo publicadas no jornal A Notícia, do Rio de Janeiro, recolhidas pela autora durante o mestrado (livro organizado em parceria com a professora Orna Messer Levin). Tal experiência configurou-se em metodologia de pesquisa para todos os projetos individuais posteriores

1 Disponível em: <https://goo.gl/WbwLqt>. Acesso em: 27 out. 2017; Disponível em: <https:// goo.gl/FwEHEa>. Acesso em: 27 out. 2017.

2 Como exemplo, citam-se as obras da professora Neyde Veneziano $(1996,2013)$, sendo que seu trabalho versava especificamente sobre o teatro de revista - o que não era o foco dos trabalhos de mestrado e doutorado da autora. 
de Neves, entre os quais destacam-se a análise de obras de Jorge Andrade (com intenso levantamento de fontes de acervo), realizada entre os anos de 2010 e 2011, e um recente projeto de pós-doutoramento sobre as operetas do século XIX, no qual se teve acesso aos acervos das bibliotecas e arquivos de Paris e de Avignon ${ }^{3}$. No entanto, além dos projetos individuais, a experiência ampliou-se para o coletivo, já que quase todas as pesquisas orientadas por Neves fazem uso também dos materiais primários para obtenção de resultados e como matéria de análise.

Para este artigo, destaca-se a metodologia de pesquisa em andamento sobre Carlos Alberto Soffredini (1939-2001), efetuada por Maria Emília Tortorella. Soffredini, um dramaturgo ainda pouco estudado, tendo em vista a importância e a qualidade de suas obras, foi também diretor e pensador do teatro brasileiro. Se o artista se destaca pela sua arrebatadora dramaturgia, seu legado envolve mais do que os textos teatrais de refinada carpintaria que deixou para o teatro brasileiro. Ele inaugurou uma forma de pesquisar o teatro e a teatralidade brasileiros, tendo influenciado as gerações posteriores. Hoje, vemos com frequência artistas da cena mergulhados em universos de matriz espetacular e performática nacional, seja de rituais festivos (como o Cavalo-Marinho), seja de rituais religiosos (como os do candomblé), ou mesmo de teatro popular (como os de mamulengo e do circo) para treinamento e aquisição de matéria-prima para a criação cênica. No entanto, tal metodologia de pesquisa era praticamente impensável há 50 anos - e Soffredini foi um dos pioneiros nessa trajetória.

Nota-se nessa pesquisa que a quantidade de materiais se faz incomensurável quando se abordam fatos mais recentes de nossa história, como é o caso desse autor e dos espetáculos ligados à sua obra. Além das fontes impressas, como periódicos e programas, praticamente únicas possibilidades existentes para o pesquisador que se debruça sobre períodos anteriores à segunda metade do século XX, o repertório se expande para uma quantidade

3 "A opereta francesa no século XIX: gêneros, encenação, recepção - para posterior estudo de seu abrasileiramento - e ações de cooperação internacional junto ao Instituto de Artes da Unicamp". Pós-doutoramento realizado no Institut de Recherche en Etudes Théâtrales (Iret) - Sorbonne Nouvelle - Paris 3. Bolsa Fapesp-SP - BPE. 
ímpar de imagens, gravações sonoras, acervos pessoais e entrevistas com participantes dos eventos a serem investigados ${ }^{4}$.

É difícil definir uma metodologia específica para o trabalho em acervos. Cada pesquisador costuma ser um descobridor, utilizando as informações para responder às questões-chave de sua tese. Este artigo objetiva divulgar um procedimento que pode, no entanto, servir de gatilho para outros pesquisadores, de outras temáticas. Existe, porém, um fator comum: abre-se caminho facilitador quando as fontes referenciais são indicadas na pesquisa publicada (a localização dos materiais, textos e peças) ou, mais ainda, quando o material é reproduzido em anexo à tese - prática generosa e felizmente comum, porque auxilia a produção de novos resultados e o caminhar segue em frente: um novo pesquisador a se debruçar sobre as mesmas obras não precisará percorrer um caminho já desbravado, poderá fazer uso indireto das fontes e, assim, ter mais tempo para explorar outras ainda não visitadas.

No caso da obra de Carlos Alberto Soffredini, a pesquisa em acervo tem se mostrado vital, se o intuito consiste em ir além da análise da dramaturgia. Mesmo esta estava inédita até o ano de 2017, quando quatro de suas peças foram publicadas (SOFFREDINI, 2017). Durante o mestrado de Tortorella (2015), as peças só podiam ser encontradas em acervos muito específicos ou com a família do autor. Tendo professores e ex-professores do Departamento de Artes Cênicas da Unicamp trabalhado com Soffredini, sendo que o grupo de teatro fundador do departamento, o Pessoal do Victor, foi responsável por impulsionar a criação de uma das peças mais belas do autor, Na Carrêra do Divino, o antigo Laboratório de Textos do departamento 5 possuía em seu acervo cópias datilografadas de várias peças do dramaturgo, o que possibilitou não só que os alunos, docentes e pesquisadores da Unicamp pudessem conhecer essa obra - desconhecida em outras instituições - como possibilitou também a redação dos projetos de pesquisa de Tortorella, iniciados em nível de graduação.

4 Em relação às obras de Soffredini que compõem o corpus de estudo de Tortorella, não foram ainda localizados vídeos mas, obviamente, eles também são importantes materiais de registro de espetáculos da história recente.

5 O Laboratório de Textos, que contém acervo de diversas peças datilografas inéditas, está em processo de ser transformado em Laboratório de Dramaturgia. O acervo de peças está preservado. 
Assim, não fosse um acervo fichário de peças datilografas mantidas no laboratório, tais projetos não teriam sido realizáveis à época. Além disso, a única tese de doutoramento existente sobre as peças de Soffredini, de autoria de Eliane Lisboa, intitulada A Teatralidade na dramaturgia lírico-épica de Carlos Alberto Soffredini, também foi realizada na Unicamp, em conjunto com o Instituto de Estudos Literários (IEB). Apesar de um aumento de interesse sobre sua obra, nos meios acadêmicos principalmente, o autor continua desconhecido, em comparação com a qualidade de sua dramaturgia e com seu papel precursor na pesquisa empírica em performatividades brasileiras, especialmente o circo-teatro. Suas iniciativas, completamente inovadoras na década de 1970, possibilitaram que diversos artistas da cena de sua época e de período imediatamente posterior entendessem a riqueza representada e a amplitude de campo de trabalho proporcionados pela cultura popular brasileira para a criação cênica experimental - fugindo de concepções estrangeiras, puramente teóricas, para observar, experienciar e viver as manifestações artísticas nacionais e configurá-las para uma prática cênica outra.

Soffredini foi um dos primeiros a trabalhar sob os parâmetros de um modo de fazer cênico contemporâneo, vivenciado pelo chamado teatro de grupo. Além disso, sua intervenção como mestre de vários artistas mostra como não apenas sua dramaturgia carece de estudos mais verticalizados, mas toda sua carreira merece ser melhor investigada. Em tempo, é possível que a trajetória de Soffredini possa vir a ser reconhecida como tendo sido um marco fundamental da passagem do teatro moderno, que se iniciou na década de 1940 no país, para o teatro contemporâneo, marcado pelas pesquisas de campo de coletivos teatrais e pelo chamado processo colaborativo (ABREU, 2004).

Essa perspectiva de localizar a contribuição real de Soffredini dentro da história recente do teatro brasileiro surgiu da pesquisa em acervo, em que foram encontradas notícias com trechos como:

Soffredini sabe que não adianta criar uma nova linguagem para arte popular e que é preciso usar a linguagem já existente. Mas, quando o já existente é manipulado por Soffredini, existe sempre a perspectiva do novo e do original. Na sua obra, isso já é uma norma (UM NOVO..., 1976, p. 25) 
Escrita às vésperas da estreia de A Vida do Grande Dom Quixote de La Mancha e do Gordo Sancho Pança, a crônica em questão alcança vislumbrar um aspecto fundamental da inovação de Soffredini: não a descoberta de algo novo, mas a descoberta da necessidade de se firmar um novo olhar sobre o tradicional, o popular, no caso. Esse novo olhar, que o autor descreve no seu ensaio De um trabalhador sobre seu trabalho (1980), consistia na base da construção teatral de Soffredini, e em seu projeto estético.

A análise dos materiais primários levantados se combina, na tese de Tortorella, com as leituras referenciais. A partir desses materiais esgaravatados em rigoroso trabalho de busca, a autora pôde, por exemplo, ter ideia de maneira mais fundante sobre qual de fato foi a expressividade da encenação do espetáculo citado anteriormente, A Vida do Grande Dom Quixote de La Mancha e do Gordo Sancho Pança, apresentado nas ruas. Esse espetáculo, que pode ter sido um dos marcos inaugurais de uma nova maneira de se fazer teatro em São Paulo - em todos os sentidos (prática, dramaturgia, pesquisa, espaço cênico, relação com o público etc.) - teve função impactante num meio teatral no qual o teatro de rua sem o propósito de militância política praticamente não existia.

As imagens, notícias de jornal e entrevistas trouxeram dados inéditos de nosso teatro sobre esse momento que nos parece crucial, mas que está quase esquecido. A pesquisa em acervo aliada às leituras das poucas obras que comentam o espetáculo, de autoria do próprio Soffredini (1980), de Sílvia Fernandes (2000) e de Rubens Brito $(2004,2006)$ - este atuou no espetáculo -, tornou patente o espanto que aquela prática cênica inovadora proporcionou à classe teatral paulistana, tanto que os atores da cidade solicitaram ao grupo Mambembe que ministrasse um curso sobre a técnica utilizada por eles. A aula aconteceu no Teatro de Arena, com a presença de vários artistas (BRITO, 2004). Esse fato, além de todo o material coletado nos acervos, instigou Tortorella e Neves a pensarem numa merecida reavaliação sobre o lugar de Soffredini na história do teatro brasileiro, não apenas como excelente dramaturgo, já reconhecido, embora pouco lido e encenado, tendo em vista a qualidade de sua dramaturgia, mas também como um marco em nossa história recente - tese ainda em desenvolvimento. 
Assim, os indícios para encontrar as ideias desse projeto, além de sua repercussão em sua época e sua continuidade hoje, foram localizados numa investigação incessante por fontes primárias, cujo procedimento de trabalho será descrito a seguir.

\section{Metodologias de pesquisa em acervo - o legado de Soffredini}

Há poucos anos, a pesquisa em acervos de periódicos era realizada com bastante dificuldade. Os materiais precisavam ser consultados in loco nos arquivos e bibliotecas. Eram consultados os originais em papel ou cópias microfilmadas. Não havia nenhum sistema de busca, portanto, o pesquisador deveria trilhar um fastidioso processo de verificar cada página dos jornais, geralmente a partir de referências esparsas, que poderiam ser uma data específica (da estreia de uma peça, do lançamento de um livro ou da morte de um artista), ou a periodicidade de certa coluna no jornal, entre outros. As anotações eram feitas em separado, já que não havia como copiar ou fotografar os arquivos. Seria possível, eventualmente, imprimir as imagens do microfilme, em cópias em papel bastante caras.

Hoje em dia, houve um aprimoramento incrível possibilitado pelas plataformas on-line, sendo o site da Hemeroteca Digital da Biblioteca Nacional o acervo mais amplo em termos de periódicos, o qual permite a busca por palavras-chave e a realização de cópias digitalizadas dos arquivos que são de domínio público. Para a pesquisa sobre o teatro do século XIX, por exemplo, a Hemeroteca consiste numa ferramenta incontornável. Para o pesquisador mais antigo, que trabalhou com papel e microfilme, é sempre impressionante acessá-la.

As pesquisas realizadas pelos integrantes do grupo Letra e Ato sobre aspectos da história do teatro brasileiro, em geral, iniciam-se por buscas na Hemeroteca. Assim, a pesquisa em acervo sobre a obra de Soffredini iniciou-se nessa plataforma. Além dela, foram pesquisados materiais nos acervos on-line dos jornais O Estado de S. Paulo e Folha de S.Paulo. Buscavam-se notícias sobre os espetáculos A Vida do Grande Dom Quixote de La Mancha e do Gordo Sancho Pança, de 1976; Vem Buscar-me que Ainda Sou Teu, de 
1979; e Na Carrêra do Divino, de 1979 e de 1986'. As palavras-chave utilizadas foram: "Carlos Alberto Soffredini; "Soffredini"; "Sofredini" (com a grafia errada, pois assim havia aparecido em uma matéria de 1967); "Na Carrêra do Divino"; "Vem Buscar-me que Ainda Sou Teu”; "A Vida do Grande Dom Quixote de La Mancha e do Gordo Sancho Pança”; "Grupo Mambembe”; "Projeto Mambembe do Sesc"; "Pessoal do Victor"; "Núcleo Estep". O período investigado foi de 1967 a 2000. Todas as edições em que os termos de buscas apareceram foram abertas.

Apesar de muitas vezes o número de ocorrência para alguns termos ter sido expressivo, as que realmente apresentavam alguma matéria de relevância, contendo críticas sobre o espetáculo, foram poucas. Por exemplo, para o termo "Soffredini", no período de 1980 a 1989 no Jornal do Brasil, que tem 181 ocorrências, porém, entre elas, apenas 7 são críticas sobre espetáculos (3 sobre Na Carrêra e 4 sobre a peça Pássaro do Poente - autoria de Soffredini, encenada pelo Grupo Ponkã sob direção de Márcio Aurélio). As outras 174 ocorrências são, basicamente, chamadas para os espetáculos, que apareciam no semanário cultural. De qualquer maneira, realizar tal levantamento nesses acervos foi muito importante pois, além dos textos críticos mais amplos encontrados (poucos, mas relevantes), a pesquisa forneceu a Tortorella melhor dimensão da carreira de Soffredini. Foram descobertos, inclusive, alguns trabalhos seus que não são mencionados em sua biografia (SOFFREDINI, 2010).

Após essa etapa de busca geral nos acervos de jornais on-line, Tortorella optou por fazer um recorte cronológico e buscar informações sobre o espetáculo Dom Quixote nos acervos do Serviço Social do Comércio (Sesc), denominado Sesc Memórias, uma vez que tal trabalho fora totalmente financiado pela instituição, desde seu processo de pesquisa e criação, até sua circulação por meio do "Projeto Mambembe do SESC.' Apesar de não haver nenhum mecanismo de busca on-line, uma conversa via e-mail foi estabelecida com a equipe do acervo, a qual se mostrou extremamente eficiente. $O$ e-mail, no qual Tortorella apresentava seu tema de pesquisa, foi enviado no dia 5 de abril de 2016 e respondido no mesmo dia pelo funcionário Márcio

6 A partir de agora, tais encenações serão referenciadas da seguinte maneira: Dom Quixote; Vem Buscar-me; Na Carrêra. 
Kawano, dizendo que já havia feito um primeiro levantamento sobre o Projeto Mambembe e que uma visita poderia ser agendada para a consulta de tais materiais.

A visita aconteceu no dia 7 de abril e Tortorella encontrou importantes materiais como, apenas para citar alguns exemplos, o logotipo (prospecto) do Projeto Mambembe, o Programa do Espetáculo, noticiários da Imprensa Sesc divulgando o Projeto Mambembe, uma lista de apresentações do espetáculo Dom Quixote, em 1976 e em 1977 na cidade de São Paulo, e uma clipagem sobre o Projeto Mambembe do Sesc na imprensa em geral. Todos os materiais que interessavam à pesquisadora foram escaneados por Márcio e enviados por e-mail. Além disso, nos dias que se seguiu, o funcionário continuou as buscas no conjunto do acervo para encontrar possíveis outros materiais - existe ainda muito material não tratado no acervo, o que dificulta a agilidade da busca. Infelizmente, não foi encontrado no Sesc nenhum registro visual do espetáculo, como foto ${ }^{7}$ ou vídeo.

No acervo do Centro Cultural São Paulo ${ }^{8}$, visitado em setembro de 2016, encontra-se uma quantidade bastante significativa de materiais sobre Soffredini. Especificamente sobre as encenações da pesquisa, foram encontradas fotos da peça Na Carrêra, do Grupo Pessoal do Victor, e também de Vem Buscar-me, do Grupo Mambembe, além da gravação sonora dos dois espetáculos. Como o processo para poder copiar os materiais do acervo é mais complicado e também porque havia a possibilidade de encontrá-los em outros acervos, ou mesmo junto com os artistas que participaram dos espetáculos e aos quais Tortorella iria entrevistar, a pesquisadora ainda não deu entrada nas burocracias para o pedido de cópia e deu continuidade à busca.

No sistema de busca on-line dos Acervos dos Arquivos Históricos da Unicamp ${ }^{9}$, entre os quais consta o acervo Arquivo Edgar Leunroth (AEL), não foi encontrada ocorrência para os termos de busca já citados, a não ser para o termo Grupo de Teatro Mambembe, para o qual apareceu uma ocorrência na Coleção Leon Hirszman (AEL) - mas, em visita às dependências do Acervo,

7 Tortorella encontrou fotos do espetáculo Dom Quixote nos acervos pessoais de alguns artistas entrevistados.

8 Disponível em: <https://goo.gl/3TJ2T8>. Acesso em: 27 out. 2017.

9 Disponível em: <https://goo.gl/4k9ym8>. Acesso em: 27 out. 2017. 
verificou-se que tratava-se de três fotos de uma apresentação do Grupo de Teatro Mambembe, mas em período posterior às encenações do corpus de pesquisa. Como alguns atores que trabalharam nessas encenações foram professores do Departamento de Artes Cênicas da Unicamp, Tortorella experimentou usar seus nomes como termo de busca e encontrou, no AEL, ocorrências para "Adilson Barros", "Márcio Tadeu," "Paulo Betti" e "Wanderley Martins" - mas, como pode ser verificado posteriormente em visita física, eram fotos desses atores em outros espetáculos e/ou outros projetos que não vinculados às encenações da pesquisa.

Na consulta on-line da Fundação Casa de Rui Barbosa ${ }^{10}$, encontrou-se apenas um resultado para "Grupo de Teatro Mambembe". Trata-se de um foIheto de pesquisa de opinião sobre teatro do Grupo Mambembe - nas referências ao material, não há data. Por acreditar que esse material não contribuiria diretamente com a pesquisa, Tortorella não agendou uma visita à Fundação. No sistema de buscas Rede Web de Museus ${ }^{11}$, do governo do Rio de Janeiro, também não foram encontradas ocorrências para seus termos de busca.

No acervo da Biblioteca do Museu Lasar Segall ${ }^{12}$, de São Paulo (SP), existem diversos materiais sobre a obra de Soffredini e, portanto, Tortorella visitou a instituição no dia 17 de março de 2017. Entre os materiais relativos diretamente às encenações de estudo, destacam-se vinte notícias publicadas em jornais, entre 1979 e 1980, sobre Na Carrêra, o programa e o cartaz desse mesmo espetáculo e a edição original da Revista Teatro de 1980, na qual constam o artigo "De um trabalhador sobre seu trabalho", escrito por Soffredini após suas experiências com o Projeto Mambembe do Sesc (ou seja, aborda o espetáculo Dom Quixote), e uma fotorreportagem de Na Carrêra do Pessoal do Victor. Mas Tortorella se interessou em consultar todas as ocorrências para o termo "Soffredini", mesmo que não específicas de sua pesquisa, e encontrou materiais bastante pertinentes para pensar a estética soffrediniana como um todo - como, apenas a título de exemplo, críticas de Sábato Magaldi e João Apolinário sobre a peça $\mathrm{O}$ Cristo $\mathrm{Nu}$, uma das primeiras peças escritas por Soffredini (1965), numa edição da Revista Mensal de Teatro - Palco+Plateia.

10 Disponível em: <https://goo.gl/K2TuWz>. Acesso em: 27 out. 2017.

11 isponível em: <https://goo.gl/QA7aXt>. Acesso em: 27 out. 2017.

12 Disponível em: <https://goo.gl/cpobYV>. Acesso em: 27 out. 2017. 
No sistema de busca on-line da biblioteca da Fundação Nacional de Arte (Funarte), denominado Centro de Documentação e Informação da Funarte $(\text { Cedoc })^{13}$, digitando como termo de busca "Soffredini", o primeiro resultado que apareceu foi "A vida do Grande Dom Quixote de La Mancha e do Gordo Sancho Pança - peça teatral - autoria de Antonio José da Silva - adaptação de Carlos Alberto Soffredini” - o texto dessa adaptação fora considerado inexistente pelos artistas que participaram da peça entrevistados por Tortorella ${ }^{14}$. Porém, ao visitar os acervos da Funarte no Rio de Janeiro no dia 12 de maio de 2017, a pesquisadora encontrou apenas uma cópia do texto de Antonio José e não a adaptação de Soffredini. Ao informar os funcionários sobre o erro da referência, eles pesquisaram na base de dados, mas não conseguiram encontrar informações para afirmar se existe ou não no acervo a versão de Soffredini. Fora esse equívoco ${ }^{15}$, o Cedoc possui uma quantidade expressiva de materiais sobre o artista, os quais foram consultados e, quando possível, fotografados pela pesquisadora, os quais serão de grande valia para a elaboração da tese sobre a estética soffrediniana.

Além dos acervos dessas instituições, outra rica fonte de materiais foram os acervos pessoais dos artistas que participaram das encenações, os quais a pesquisadora entrevistou ao longo do segundo semestre de 2016 e primeiro semestre de 2017. Ao todo, foram quinze entrevistas, a saber: com Wanderley Martins, Jesser de Souza, Calixto de Inhamuns, Noemi Gerbelli, Paulo Betti, Renata Soffredini, Ednaldo Freire, Eduardo Coutinho, Douglas Salgado, Flávio Dias, Genézio de Barros, Rosi Campos, Tato Fischer e Berenice Raulino. Além do conteúdo das entrevistas em si, que serão uma fonte inédita e importante para o desenvolvimento da pesquisa, Tortorella encontrou nesses artistas uma quantidade enorme e diversa de materiais, tanto sobre as encenações específicas do corpus de estudo quanto sobre a obra de Soffredini como um todo.

13 Disponível em: <https://goo.gl/jifkd4>. Acesso em: 27 out. 2017.

14 Como o processo de adaptação do texto de Antônio José se deu em sala de ensaio, a partir tanto de propostas de Soffredini como também de improvisação dos atores, e cada um era responsável por anotar ou decorar exclusivamente suas próprias falas, os atores afirmam que não houve uma organização da versão final do texto do espetáculo.

15 Até o momento (set. 2017), o termo ainda não foi alterado no sistema de buscas on-line do arquivo. 
Ao longo de sua trajetória de pesquisa, desde a graduação até o mestrado, Tortorella teve acesso apenas aos textos de Soffredini. Não sendo muito extensa a bibliografia crítica e acadêmica sobre o autor ${ }^{16}$, ao propor um estudo de doutorado sobre obra de Soffredini, a pesquisadora sentiu necessidade de lançar-se numa investigação em busca de materiais e informações sobre as encenações de suas peças, com a pretensão de enveredar para um estudo, até agora inexistente, sobre a estética soffrediniana dos textos aos palcos. Percebe-se, portanto, que realizar as mencionadas entrevistas, bem como as buscas nos acervos institucionais, consistiu numa etapa bastante crucial para os objetivos desta pesquisa.

\section{Referências bibliográficas}

ABREU, L. A. Processo colaborativo: relato e reflexões sobre uma experiência de criação. Cadernos da ELT, Santo André, n. 2, jun. 2004. Disponível em: <https:// goo.gl/ewtD6a>. Acesso em: 17 set. 2017.

BRITO, R. S. O grupo de teatro Mambembe e o Circo Teatro. Sala Preta, São Paulo, v. 6, p. 79-85, nov. 2006. Disponível em: <https://goo.gl/ydqjDA>. Acesso em: 26 out. 2017.

. Teatro de rua: princípios, elementos e procedimentos. 2004. 226 f. Tese (Livre Docência em Artes) - Universidade Estadual de Campinas, Campinas, 2004. FARIA, J. R. José de Alencar e o teatro. São Paulo: Perspectiva, 1987. O teatro realista no Brasil: 1855-1865. São Paulo: Perspectiva, 1993. FERNANDES, S. Grupos teatrais: anos 70. Campinas: Editora da Unicamp, 2000. NEVES, L. O. $O$ teatro: Artur Azevedo e as crônicas da Capital Federal (1894-1908). 2002. 742 f. Dissertação (Mestrado em Teoria e História Literária) - Instituto de Estudos da Linguagem, Universidade Estadual de Campinas, Campinas, 2002.

As comédias de Artur Azevedo: em busca da história. 2006. 458 f. Tese (Doutorado em Teoria e História Literária) - Universidade Estadual de Campinas, Campinas, 2006.

NEVES, L. O.; LEVIN, O. M. O theatro: crônicas de Arthur Azevedo (1894-1908). Campinas: Editora da Unicamp, 2009.

PINTO, M. E. T. N. O popular no moderno teatro brasileiro: das projeções de Alcântara Machado às realizações de Carlos Alberto Soffredini. 2015. 114 f. Dissertação (Mestrado em Artes da Cena) - Universidade Estadual de Campinas, Campinas, 2015.

16 Existem importantes trabalhos, tais como alguns citados aqui. No entanto, esses trabalhos não exploram a relação texto-cena de forma ampliada, enquanto projeto estético do autor. 
PRADO, D. A. João Caetano. São Paulo: Perspectiva, 1972.

O drama romântico brasileiro. São Paulo: Perspectiva, 1996.

SOFFREDINI, C. A. De um trabalhador sobre seu trabalho. Revista Teatro, São Paulo, ano I, n. 0, jun./jul. 1980.

Soffredini: obras principais. São Paulo: Giostri, 2017.

SOFFREDINI, R. Carlos Alberto Soffredini: serragem nas veias. São Paulo: Imprensa Oficial do Estado de São Paulo, 2010.

UM NOVO mecenas para o teatro: o comércio. O Estado de São Paulo, São Paulo, 23 ago. 1976. Jornal da Tarde, p. 25.

Recebido em 19/09/2017

Aprovado em 21/10/2017

Publicado em 26/12/2017 